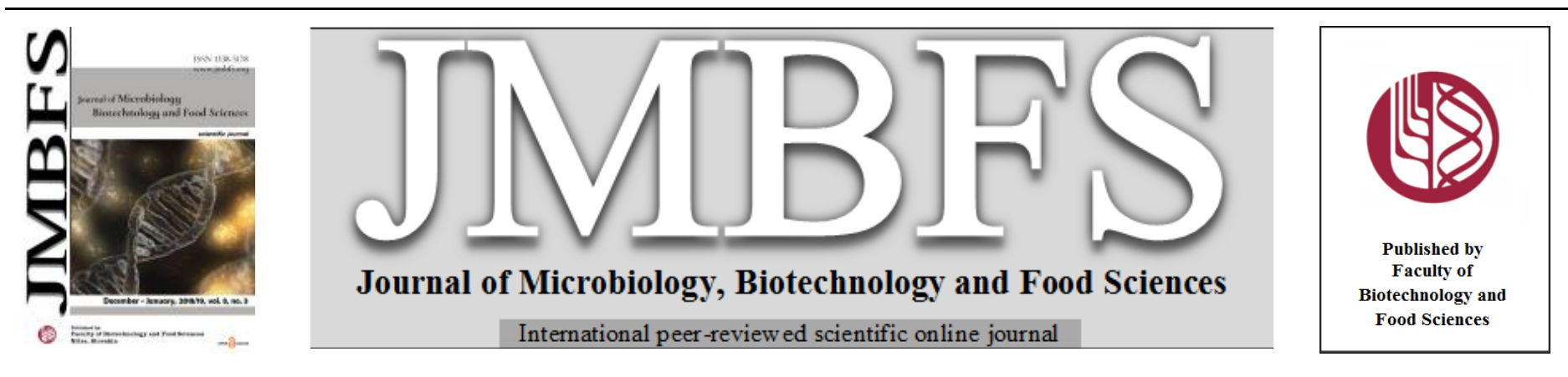

\title{
OPTIMIZATION OF FREEZING CONDITIONS FOR CRYOPRESERVATION OF RAT SPERMATOGONIAL STEM CELL
}

\author{
Tetyana Syvyk*1, Leonid Djachenko ${ }^{1}$, Andrew Syvyk ${ }^{2}$ \\ Address(es): Dr. Andrew Syvyk, \\ ${ }^{1}$ Bila Tserkva National Agrarian University, Department of Biotechnology, 8/1, Soborna Sq., 09117 Bila Tserkva, Ukraine, +38(068) 4903324. \\ ${ }^{2}$ Blinn College, Faculty, Department of Biology, 902 College Ave, 77833 Brenham, USA, +1(214) 6299918.
}

*Corresponding author: dr.syvyk@hotmail.com

doi: $10.15414 /$ jmbfs.2018-19.8.3.947-950

\section{ARTICLE INFO}

Received 12. 8. 2018

Revised 16. 10. 2018

Accepted 17. 10. 2018

Published 1. 12. 2018

Regular article OPEN $\partial_{\text {ACCESS }}$

\begin{abstract}
Different cell types demonstrate an individual response to the doses of DMSO in freezing media that cannot be calculated empirically. Such situation requires experimental adjustment of the dose of the main cryoprotectant for each cell type. The purpose of the work was to optimize the basic composition of the cryopreservation medium for the rat spermatogonial cell lines, to investigate the time period of the initial storage of the cells at $-80^{\circ} \mathrm{C}$, as well as the effect of the ratio of volume of the freezing medium to the number of cells on their subsequent survival after recovery. Our data demonstrate that the $8 \%$ DMSO is the most effective concentration of the cryoprotectant. Furthermore, we tested different time of initial storage of cryovials in a commonly used "Mr. Frosty" Freezing Container at $-80^{\circ} \mathrm{C}$. Our results suggest that 12 hours period (overnight) provides enough time for primary freezing step at $-80^{\circ} \mathrm{C}$. Optimization of the volume of freezing medium revealed, that $0.5 \mathrm{ml}$, compared with $1.0 \mathrm{ml}$ of medium for rat spermatogonial stem cells allows more effective preservation and long-time cryostorage of low numbers of cells $\left(3 \times 10^{4}\right)$ with successful recovery of up to $50 \%$ of the frozen cell population. Additionally, we attempted to improve the freezing medium composition by supplementing its base formulation with sucrose and/or trehalose. The use of optimal concentration of DMSO (8\%) in the medium in combination with a $200 \mathrm{mM}$ of trehalose resulted in an increase of spermatogonia viability after recovery by more than $12 \%$ compared to the original composition of SG (Spermatogonia Growth) medium containing 10\% of DMSO.
\end{abstract}

Keywords: spermatogonial stem cell, mutant spermatogonial lines, spermatogonial culture medium, DMSO, cryopreservation

\section{INTRODUCTION}

Historically, rats represent the most widely applied non-primate mammals to model disease processes (Chapman et al., 2011; Syvyk et al., 2017). Given the rate at which genetic know-how for editing rat genomes is accelerating, and the ever expanding rat genomics toolbox, strategies for preserving rat germline resources are becoming even more essential (Ivics et al., 2011; Izsvak et al., 2010; Syvyk et al., 2018). Freeze drying spermatozoa for rederiving rat strains appears especially attractive in that archiving samples do not require low temperature storage. Recent studies further demonstrate successful rederivation of rat strains from freeze dried sperm after storage at $4^{\circ} \mathrm{C}$ for more than five years (Hirabayashi et al., 2005; Hochi et al., 2008; Kaneko and Serikawa, 2012). In addition to preserving sperm, unique biology of the testis allows it to mobilize mutant sperm production from large numbers of donor sperm stem cells, a trait being exploited to help build a genome wide bank of mutant rat germlines (Chapman et al., 2011; Stacey and Masters, 2008).

Apart from studying spermatogenesis itself, male germ stem cell can be utilized for generation of random or predetermined genetic alterations and transfer those alterations onto a whole organism via direct germline transmission (Brinster and Nagano, 1998; Chapman et al., 2011; Wu et al., 2012; Syvyk et al., 2018). In this case, a robust and reproducible methodology for primary culture preparation and storage with subsequent line derivation is needed. It is especially important when large-scale projects, such as mutant line generation, involves a large number of samples that can be collected and deposited to cryo-banks of frozen spermatogenic cell lines for downstream manipulations or applications. Successful recovery of the mutant cell lines and ultimately re-establishment of the animal line is of paramount importance for any research project and for generation of mutant libraries especially (Chapman et al., 2011; Ivics et al., 2011; Izsvak et al., 2010). For efficient utilization of the resources, once identified a mutant animal line can serve as a source for a primary spermatogenic cell culture and can be cryopreserved until the necessity for the establishment of the mutant animal line arises. The spermatogonial cell lines could be recovered from cryopreserved cultures and transplanted into an appropriate recipient for the re-establishment of mutant animal lines upon request (Kanatsu-Shinohara et al., 2003; Kanatsu-Shinohara et al., 2011; Mirzapour et al., 2013).

For cryopreservation of above mentioned cultures, we used our standard SG (Spermatogonia Growth) medium supplemented with $10 \% \mathrm{v} / \mathrm{v}$ DMSO which is the most widely accepted dosage of this intracellular cryoprotectant for a broad range of cell types (Pegg, 2015; Stacey and Dowall, 2007; Wu et al., 2012). However, different cell types demonstrate an individual response to the doses of DMSO in freezing media that cannot be calculated empirically. Such situation requires experimental adjustment of the dose of the main cryoprotectant for each cell type. Since the experimental adjustment for rat spermatogenic cell never being done before we decided to cover this gap and test range of DMSO concentration in SG based freezing medium for established spermatogonial cell lines. Moreover, in the available literature we were not able to find any experimental data for the time of initial storage at $-80^{\circ} \mathrm{C}$ (Aliakbari et al., 2016; Chapman et al., 2011; Pegg, 2015). Therefore, we attempted to investigate whether the time of initial storage at $-80^{\circ} \mathrm{C}$ influences cell survival upon thawing. Additionally, generation of mutant germ cell lines can involve clonal line derivation from the libraries of modified spermatogonia. In this case, preservation of a small number of cells may be required (Syvyk et al., 2017) Therefore, we endeavored to optimize the volume of freezing medium with respect to the cell density. Taking into account constantly improving freezing medium composition we tested abilities of trehalose and sucrose additives to enhance the viability of rat spermatogonia after recovery from cryopreservation (Buchanan et al., 2004; Lee et al., 2013; Motta et al., 2014; Rodrigues et al., 2008).

Commutatively, the purpose of presented study was optimization of freezing medium composition and conditions for cryopreservation of rat spermatogonial stem cell. 


\section{MATERIAL AND METHODS}

\section{Animal lines, Care and Use}

All of the protocols for use of animals in this study were approved by the IACUC at the University of Texas Southwestern Medical Center at Dallas as certified by the Association for Assessment and Accreditation of Laboratory Animal Care International (AALAC). Rats were kept in individually ventilated cages (Lab Products 2100) in dedicated facilities with climate control set to $22^{\circ} \mathrm{C}$, and $50 \%$ humidity. Animals were kept under a 12/12 hours light/dark cycle with lights on at 6 a.m. and off at 6 p.m. Wildtype Sprague Dawley rats were from Harlan, Inc., and used previously to generate SD-tg(ESptd1-EGFP) rats (Cronkhite et al.,

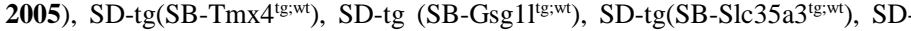
$\operatorname{tg}\left(\right.$ SBPan3 $\left.{ }^{\text {tg;wt }}\right)$, SD-tg(SB-Zmynd8 $\left.{ }^{\text {tg;wt }}\right)$ rats; SD-tg(SB-Dazl-dtTomato) and SDTG(GCS-EGFP (Cronkhite et al., 2005; Izsvak et al., 2010).

Optimizing DMSO concentration in SG Freezing Medium, improvement of the medium composition with trehalose and sucrose

Effect of DMSO concentration in SG Freezing Medium was tested on collagen nonbinding fractions of seminiferous epithelium cells from 30 wildtype Sprague Dawley rats at 22 days of age/experiment ( $\mathrm{n}=3$ experiment). It was expected that freshly isolated collagen non-binding testis cells consist of $~ 90 \%$ DAZL+, VIMspermatogenic cells, and $\sim 10 \%$ DAZL-, VIM+ somatic cells (Pegg, 2015; Stacey and Dowall, 2007). Isolation of rat spermatogonial stem cells was conducted as described before (Chapman et al., 2011). Isolated fractions of spermatogenic cells from each individual isolation were divided equally into 16 vials for cryopreservation in SG Freezing Medium containing $0 ; 6 ; 8 ; 10 ; 12 ; 14 ; 16$ or $18 \%$ v/v DMSO (i.e. duplicate vials/DMSO concentration). SG Medium without DMSO did not support cryopreservation of viable spermatogonia. One vial of cells frozen at each DMSO concentration/experiment was thawed three months after cryopreservation to record numbers of viable cells. The second vial of cells frozen at each DMSO concentration from each experiment was thawed and analyzed similarly after cryopreservation for 14 months. Similar DMSO concentrations were tested for cryopreserving and measuring post-thaw viability of 3 different established rat spermatogonial lines (wildtype line, passage 16; tgGCS-EGFP line, passage 20; tgSB-Zmynd8tg;wt line, passage 15) frozen as duplicate sets/DMSO concentration at $10^{6}$ cells in $1 \mathrm{ml} \mathrm{SG}$ Freezing Medium/vial after 3 and 14 months of cryopreservation. Viability of two spermatogonial cell lines, tgGCS-EGFP and tgGCS-dtTomato, was also tested after being cryopreserved for 1 and 2 months, respectively in $0.5 \mathrm{ml} \mathrm{SG}$ freezing medium (8\% or $10 \%$ DMSO v/v) containing $50 \mathrm{mM}, 100 \mathrm{mM}$ or $200 \mathrm{mM}$ trehalose (T0167-10G, Sigma), or, $70 \mathrm{mM}$ or $140 \mathrm{mM}$ sucrose (S24060-1000, Research Products International Corp) at $3 \times 10^{4}$ cells/vial. Hemocytometer (cat. No. 02 671-6, Fisher, Inc.) was used to count the cells and estimate number of the viable cells by Trypan Blue (T6146-25G, Sigma Inc.) Additionally, LIVE/DEAD ${ }^{\circledR}$ Cell Viability Assays (cat. N L7013, Life Technologies Corp.) was used according to manufacturer instruction.

Testing different time of initial freezing step at $-80^{\circ} \mathrm{C}$ in "Mr. Frosty" freezing container

We used primary culture of collagen-none-binding spermatogenic cells isolated from two sets of 22-23 days old pups of GCS-GFP line from two separate litters and one set of 23 days old pups of T138 line of the single litter. Cultures were prepared as described earlier (Chapman et al., 2011). From the first litter of GCS-EGFP pups (7 animals) we prepared 18 vials with $3.0-3.5 \times 10^{6}$ cells/vial and froze them in the "Mr. Frosty" container at $-80^{\circ} \mathrm{C}$ : 6 vials for 12 hours; 6 vials for 24 hours and 6 vials for 48 hours followed by transfer into a liquid nitrogen cryostorage unit.

Influence of DMSO concentration and time of the initial freezing at $-80^{\circ} \mathrm{C}$ on viability of the cryopreserved cells were also examined on 2 different established rat spermatogonial lines (wildtype line, passage 10; tgGCS-EGFP line, passage 14) frozen in $1 \mathrm{ml} \mathrm{SG}$ Freezing. Based on previous result we selected 6, 8, and $10 \%$ of DMSO v/v to be tested. For each DMSO concentration 18 vials containing $10^{6}$ cells/vial in $1 \mathrm{ml}$ of SG freeze medium were prepared and frozen in the "Mr. Frosty" container at $-80^{\circ} \mathrm{C}: 6$ vials for 12 hours; 6 vials for 24 hours and 6 vials for 48 hours followed by transfer into a liquid nitrogen cryostorage unit. Frozen spermatogonia were recovered after 3 months of cryopreservation in a liquid nitrogen cryostorage tank. Viability of the thawed cell was estimated by Trypan Blue Exclusion Test.

\section{Cryopreservation of low cell number of spermatogonia from cell lines}

WT (wild type) spermatogonial cell line at passage 13 and T138 spermatogonial cell line at passage 10 were used to test a possibility of long time cryopreservation of low quantities of SSC (Spermatogonia Stem Cells). Sets of 27 vials of cells for these two lines were prepared: each set contained 3 vials with $3 \times 10^{5}, 10^{5}$ and $3 \times 10^{4}$ cells re-suspended in $1 \mathrm{ml}, 500 \mu 1$ and $250 \mu 1$ of SG freezing medium containing $8 \%$ DMSO (v/v). Total 9 different conditions with three vials per condition for each cell line were prepared. Cells were thawed and recovered after 10 months of cryopreservation, counted and tested for viability by Trypan Blue Exclusion Test.

For study immunocytochemistry germ cells cultivated on the laminin were fixed by $4 \%$ paraformaldehyde in $1 \mathrm{M}$ phosphate buffer $(\mathrm{pH} \mathrm{7,2)}$ for $10 \mathrm{~min}$. After fixation cells were washed twice with a PBS (PBS; Invitrogen Inc, cat no. 14040182 ) and permeabilized with $0.1 \%(\mathrm{v} / \mathrm{v})$ Triton X-100 in PBS. The cells were then washed twice with PBS and incubated in $1 \%(\mathrm{v} / \mathrm{v})$ solution of blocking reagent (Roche, Applied Biosystem) for 1 hour at $\sim 22-24^{\circ} \mathrm{C}$. After removing the blocking reagent cell were incubated overnight at $\sim 22-24^{\circ} \mathrm{C}$ with primary antibody diluted into fresh blocking reagent. The mouse anti-human PLZF IgG (Calbiochem, cat no. OP128, clone ID 2A9) were diluted 1:500, the home prepared rabbit anti-DAZL-3 IgG (Chapman et al., 2011) were diluted to 250 $\mathrm{ng} / \mathrm{ml}$ in blocking reagent. After incubation with primary antibody, cells were washed with PBS and then incubated for 40 min at $\sim 22-24^{\circ} \mathrm{C}$ with goat antimouse Alexa Fluor 594 or goat anti-rabbit Alexa Fluor 488 secondary antibodies (Invitrogen, Inc) diluted to $5 \mu \mathrm{g} / \mathrm{ml}$ in PBS containing $5 \mu \mathrm{g} / \mathrm{ml}$ Hoechst 33342 dye (Molecular probes, cat no. H3570). After incubation with secondary antibodies cells were washed with PBS and viewed using an inverted Olympus IX70 microscope (Olympus, Inc.)

The experiments were replicated three times and the data points of live cell counts are presented as the standard error of the mean \pm SEM calculated using Microsoft Excel software.

\section{RESULTS AND DISCUSSION}

Optimizing DMSO concentration in SG Freezing Medium for established spermatogonial cell lines

The effectiveness of SG Freezing Medium containing different DMSO concentrations $(6,8,10,12,14,16$ and $18 \% \mathrm{v} / \mathrm{v})$ for cryopreserving 3 established rat spermatogonial lines (wildtype, $\operatorname{tgGCS}$-EGFP, $\operatorname{tgSB}-Z m y n d 8^{\text {gt:wt }}$ ) was tested. Cells suspended in each respective freezing medium at a density of $10^{6}$ cells $/ \mathrm{ml}$ were aliquoted into vials, pre-cooled at $-80^{\circ} \mathrm{C}$ for 48 hours and then transferred into the liquid nitrogen storage for cryopreservation. Post-thaw viability of cells from duplicate vials/DMSO concentration was analyzed after 3 and 14 months of cryostorage (Fig 1, A).

Similar results were obtained from each of the three lines at both time points, with spermatogonial viability highest in SG Freezing Medium containing 8\% DMSO ( 3 months $44.2 \pm 1.8 \%$ viability, 14 months $43.9 \pm 0.9 \%$ viability; \pm SEM, $\mathrm{n}=3$ lines), and lowest in SG Freezing Medium containing 18\% DMSO (Fig1, A). Accordingly, the greatest recovery of viable spermatogonia was obtained using SG Freezing Medium containing 8\% DMSO (3 months, $39.7 \pm 0.94 \%$ recovered 14 months $39.0 \pm 2.8 \%$ recovered, \pm SEM, $n=3$ lines) (Fig 1, B). Estimates of cell viability obtained using Trypan Blue exclusion were verified in representative samples using the LIVE/DEAD fluorescence assay (Fig 1, C). Thus, as found with studies using freshly isolated collagen non-binding testis cells, $8 \%$ DMSO in SG Freezing Medium provided the most optimal concentration of cryoprotectant for established spermatogonial lines.

\section{Effects of storage time at $-80^{\circ} \mathrm{C}$ on cryopreserving of spermatogonia}

Current protocols for cryopreservation of germ cell have a different suggestion for the duration of the initial time of cooling and storage of cell cultures at $-80^{\circ} \mathrm{C}$ using "Mr. Frosty" freezing container (Pegg, 2015; Stacey and Dowall, 2007). Theoretically, two hours is enough to reach the desired temperature. Practically the freezing container remains at $-80^{\circ} \mathrm{C}$ at least overnight or even for a couple of days. Here, we evaluated the effects of initial storage time at $-80^{\circ} \mathrm{C}$ on the postthaw viability of spermatogonia cryopreserved using SG Freezing Medium containing $8 \%$ DMSO.

Collagen non-binding testis cells isolated from 3 independent cultures (tgGCSEGFP rats, $n=2$ cultures; tgGESptd 1 rats, $n=1$ culture) were aliquoted into vials and stored in the "Mr. Frosty" freezing container at $-80^{\circ} \mathrm{C}$ for $12 ; 24$ or 48 hours. Vials of frozen cells were then transferred into liquid nitrogen and stored for 10 months. After 10 months of cryopreservation, post-thaw viability of cells obtained from the first tgGCS-EGFP rat was $57.3 \pm 1.3 \%$; $54.7 \pm 2.0 \%$ and $53.7 \pm 0.99 \%$ at their respective, 12,24 and 48 hours time points ( $\mathrm{n}=3$ vials/point) (Fig 2, A). Similar results were obtained with cells from the second tgGCS-EGFP rat (Fig 2, A). Likewise, post-thaw viability of cells obtained from tgGESptd1 rats was $59.0 \pm 1.9 \% ; 57.2 \pm 1.9 \%$ and $56.8 \% \pm 2.5 \%$ for their corresponding time points ( $\mathrm{n}=3$ vials/point) (Fig 2, A).

Thus, the recovered cells demonstrated an incremental decrease in cell viability as a function of time at $-80^{\circ} \mathrm{C}$, which dropped by $\sim 3.5 \%$ between the 12 and 48 hours time points (Fig 2, A). Relative numbers of germline and somatic testis cells recovered/vial were also counted after culturing them on laminin in SG medium for 1 and 6 days (Fig 2, B). Ratios of somatic to germline cells remained relatively consistent over time in culture for each storage period at $-80^{\circ} \mathrm{C}$ tested (Fig 2, B). For example, after 1 and 6 days in culture on laminin this ratio was $\sim 75: 25 \%$ and $\sim 76: 24 \%$ (Somatic:Germline \%), respectively, for the 12 hours 
storage period using SG Freezing Medium containing 8\% DMSO (average values from 1 tgGCS-EGFP rat and 1 tgGESptd 1 rat).

Moreover, similar results were obtained after cryopreserving of established rat spermatogonial lines, as no statistically significant data on spermatogonial viability post-thaw were measured as a function of storage time at $-80^{\circ} \mathrm{C}$ using SG Freezing Medium containing 6; 8 or 10\% DMSO (Fig 2, C).

A Wildtype -o $\operatorname{tg} S B-Z y m n d 8$ -
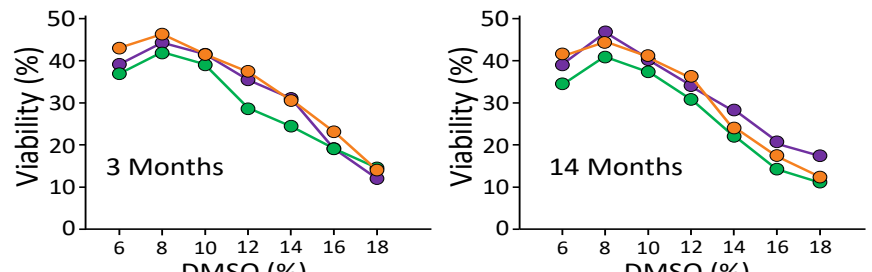

B
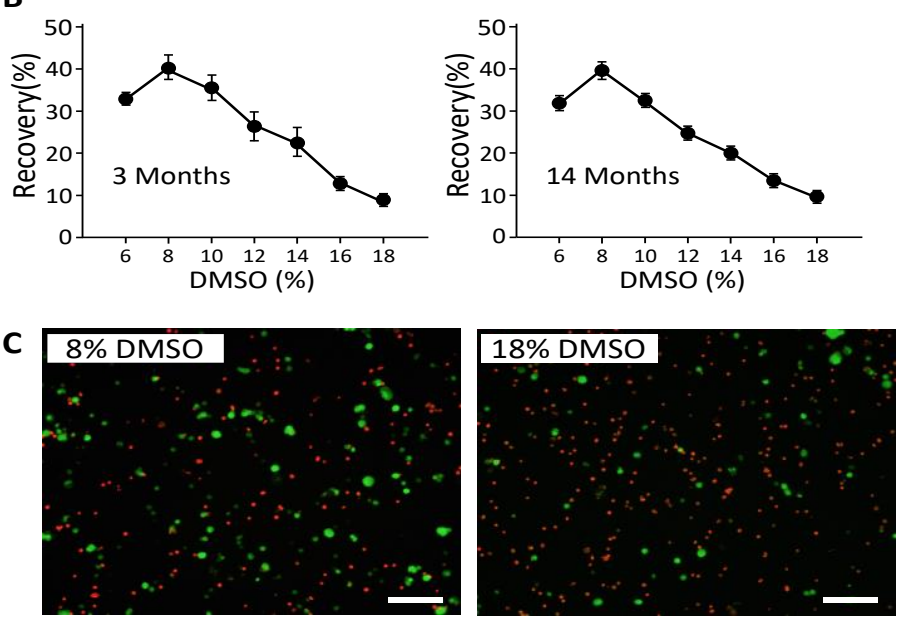

Live

Dead

Figure 1 Effects of DMSO on Cryopreserving of Rat Spermatogonial Lines in SG Medium. A. Viability of 3 rat spermatogonial lines post-thaw after cryopreservation at $10^{6}$ cells/vial for 3 months (left) and 14 months (right) B. Percentage of viable spermatogonia recovered post-thaw from total viable cells frozen in the same stocks described in panel A after 3 months (left) and 14 months (right) of cryopreservation. Error bars represent $\pm S E M, n=3$ rat spermatogonial lines. C. Illustration of cell viability post-thaw after cryopreservation in SG freezing media supplemented with $8 \%$ and $18 \%$ DMSO. Spermatogonia from Zmynd8 $8^{\text {t:wt }}$ rats were recovered from cryopreservation and stained using the Live/Dead assay kit. Live cells (green fluorescence); Dead cells (red fluorescence). Scale Bar, $100 \mu \mathrm{m}$

Effects of SG Freezing Medium volume and cell concentration on spermatogonial cryopreservation

Because optimal cryopreservation of spermatogonial stem cells in SG Freezing Medium could be affected by cell concentration and/or freezing medium volume/vial, we investigated the post-thaw viability of spermatogonial lines cryopreserved as a function of these two parameters.

Two rat spermatogonial lines (wildtype line, passage 13; tgGESptd1 line, passage 10 ) were cryopreserved in SG Freezing Medium containing 8\% DMSO in three different volumes $(250 \mu \mathrm{l}, 500 \mu \mathrm{l}$ and $1000 \mu \mathrm{l} / \mathrm{vial})$ containing cells at three different concentrations $\left(3 \times 10^{5}, 10^{5}\right.$ and $3 \times 10^{4}$ cells/unit, volume/vial) (Fig 3). As an example, mean post-thaw viability of wildtype and tgGESptd 1 rat spermatogonial lines cryopreserved at $3 \times 10^{4}$ cells/vial was $44.4 \pm 2.7 \%$; $45.9 \pm 2.3 \%$ and $41.4 \pm 2.2 \%$ at $0.25 ; 0.5$ and $1.0 \mathrm{ml} / \mathrm{vial}$, respectively ( $\mathrm{n}=6$ vials or 3 vials/line, \pm SEM) (Fig 3).

Therefore, at this lower cell concentration/vial, spermatogonial viability was $~ 7 \%$ higher when frozen in $0.5 \mathrm{ml}$ compared to $1 \mathrm{ml}$. Likewise, post-thaw viability of spermatogonial stocks containing the highest cell concentration/vial $\left(3 \times 10^{5}\right.$ cells) improved by $\sim 5 \%$ after cryopreservation in $1 \mathrm{ml}$ of freezing medium, compared to the lower volumes. Thus, SG Freezing Medium containing 8\% DMSO effectively supported cryopreservation of rat spermatogonial lines over a wide range of cell concentrations in different medium volumes (Fig 3).

\section{A Freshly Isolated Testis Cells}
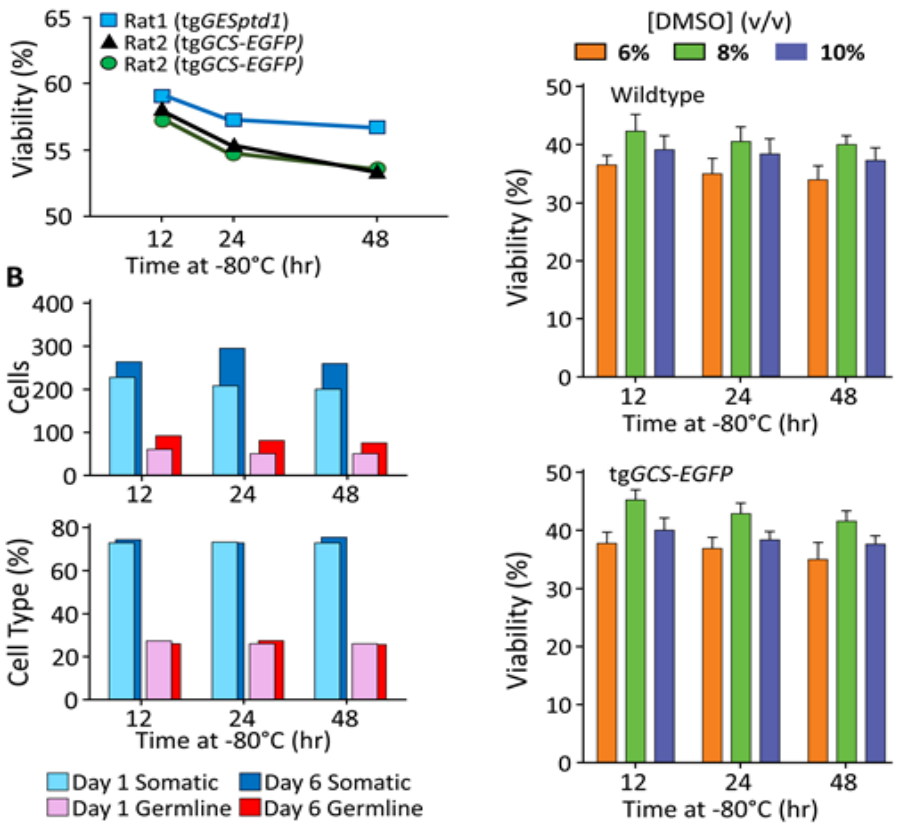

Figure $2 \mathrm{~A}$. Effects of Storage Time at $-80^{\circ} \mathrm{C}$ under isopropanol insulation ("Mr. Frosty" Container) for 12; 24 and 48 hours: viability of freshly isolated collagen non-binding testis cells after cryopreservation at 3.0-3.5 $\times 10^{6}$ cells/vial in $1 \mathrm{ml} \mathrm{SG}$ Freezing Medium supplemented with $8 \%$ DMSO for 10 months in liquid nitrogen; B. Numbers of rat Germline (tgGCS-EGFP+, PLZF+, Hoechst 33342+ nuclei) and Somatic testis cells (tgGCS-EGFP-negative; Hoechst 33342+ nuclei) recovered after 1 and 6 days of cultivation on laminin ( $\mathrm{n}=3$ vials/condition/set). (Bottom) Percent Germline and Somatic cells scored from cultures analyzed in top panel. C. Viability of spermatogonial lines from Wildtype (P10; Top panel) and tgGCS-EGFP (P14; Bottom panel) rats post-thaw after cryopreservation $\left(10^{6}\right.$ cells/vial) for 3 months in liquid nitrogen in $1 \mathrm{ml}$ of SG Freezing Medium containing $6 ; 8$ or $10 \%$ of DMSO ( $\mathrm{n}=3$ vials/condition).
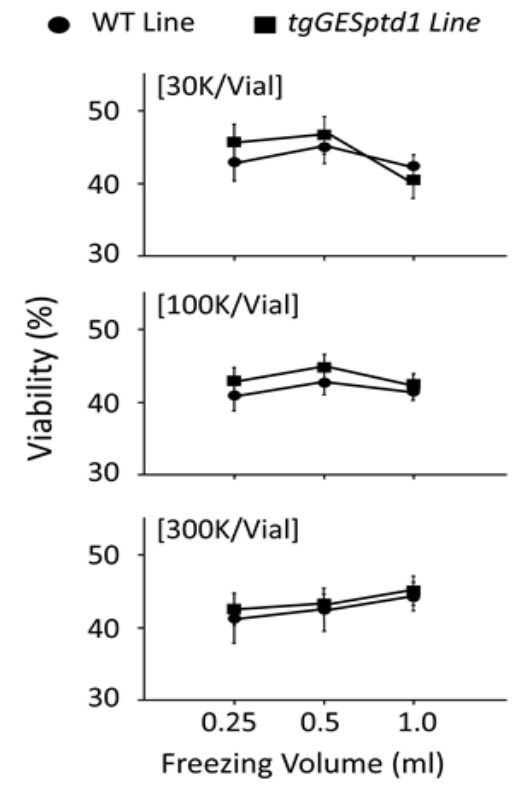

Figure 3 Viability of spermatogonial lines derived from Wildtype and tgGESptd 1 rats post-thaw after cryopreservation for 8 months at different cell concentrations in different volumes of SG Freezing Medium/vial supplemented with $8 \%$ DMSO (v/v). [30K/Vial], [100K/Vial], [300K/Vial] $=30.000,100.000$ and 300.000 cells frozen/vial at the indicated volume. $n=3$ vials/concentration/rat strain.

\section{Improvement of freezing medium composition}

Next, we evaluated the effects of trehalose (50-200 mM) and sucrose (70-140 $\mathrm{mM}$ ) on SG Freezing Medium efficiency (Fig 4). 


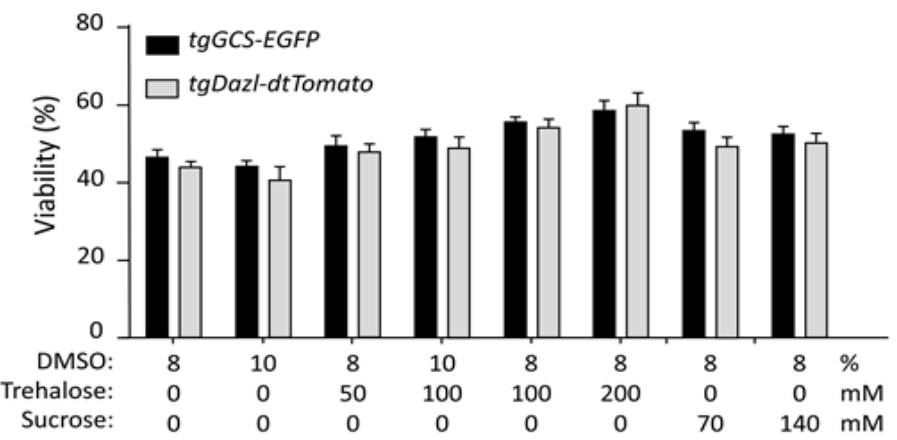

Figure 4 Post-thaw viability of spermatogonial lines derived from toGCS-EGFP and tgDazl- dtTomato rats at 1 and 3 months, respectively, after cryopreserving $3 \times 10^{4}$ cells in $0.5 \mathrm{ml} \mathrm{SG}$ Freezing Medium/vial supplemented with various concentrations of the indicated sugar cryoprotectants.

Trehalose and sucrose were previously reported to successfully improve cryopreservation of mouse spermatogonial stem cells in serum-containing and/or serum-free media (Lee et al., 2013; Motta et al., 2014). SG Freezing Medium containing $8 \%$ or $10 \%$ DMSO supplemented with each disaccharide was used for cryopreserving of two rat spermatogonial lines (tgGCS-EGFP; tgGCS-dtTomato) at $\sim 3 \times 10^{4}$ cells $/ 0.5 \mathrm{ml}$ freezing medium/vial. Each concentration of trehalose tested improved spermatogonial viability after 1 and 3 months post-thaw, with $200 \mathrm{mM}$ trehalose being the most effective additive when combined with $8 \%$ DMSO $(59.3 \pm 2.7 \%, \mathrm{SD}, \mathrm{n}=6$ vials or 3 vials/line). Under these conditions, this represents a $>30 \%$ increase in post-thaw viability ( $44 \%$ to $\sim 59 \%)$ compared to the original formulation of SG Freezing Medium containing 10\% DMSO.

Addition of sucrose at either 70 or $140 \mathrm{mM}$ also improved spermatogonial viability post-thaw in each DMSO concentration tested, but was not as effective as adding trehalose (Fig 4).

It is interesting that freshly isolated fractions of collagen non-binding testis cells are composed of $\sim 90 \%$ spermatogenic cells and $\sim 10 \%$ somatic testis cell (Chapman et al., 2011; Izsvak et al., 2010; Stacey and Dowall, 2007). However, following cryopreservation of the collagen non-binding testis cell fraction, only $\sim 10-20 \%$ of the total cell population survives, of which, there are $\sim 4$-fold more somatic cells than germ cells (Fig 2, B). Because we observed predominantly undifferentiated type A spermatogonia (PLZF+, DAZL+) and somatic cells (DAZL-) following cryopreservation and overnight culture of collagen non-binding testis cells (Fig 2, B), it appears that undefined populations of spermatogonia, as well as most spermatocytes do not survive freezing and thawing in SG Freezing medium. In summary, efficient isolation, cryopreservation and recovery of spermatogonial stem cells provides a foundation for research on spermatogenesis and transgenesis in rodents (Brinster and Nagano, 1998; Wu et al., 2014), and will likely impact our ability to preserve fertility in other species, including humans (Meistrich, 2013). Here, we evaluated the potential for further optimization of SG Freezing Medium, which is serum free, and effectively supports cryopreservation of rat spermatogonial lines. Prior to this report we had cryopreserved $>500$ mutant rat germlines using SG Freezing Medium containing 10\% DMSO as the cryoprotectant (Mutant Rat Resource at UT Southwestern), from which mutant rat strains are successfully rederived. Thus, the original formula of SG Freezing Medium provided relatively effective cryopreservation of rat spermatogonial stem cells (Wu et al., 2009). By supplementing SG Medium with $8 \%$ DMSO and $200 \mathrm{mM}$ trehalose, the efficiency of SG Freezing Medium for cryopreserving rat germlines has been optimized even further.

Consequently, effective isolation, cryopreservation and regeneration of spermatogonial stem cells are the key components for the study of spermatogenesis and spermatogonia mediated transgenesis (Rodriguez-Sosa et al., 2014; Shinohara et al., 2000; Stacey and Dowall, 2007).

\section{CONCLUSION}

1. An optimal storage time of spermatogonial cells at $-80^{\circ} \mathrm{C}$ can be taken as 12 hours.

2. The viability of the low number of spermatogonia $\left(3 \times 10^{4}\right)$ frozen in $0.5 \mathrm{ml}$ of freezing medium, compared with a volume of $1.0 \mathrm{ml}$ of medium, increases by $7 \%$.

3. The use of optimal DMSO (8\%) in the medium in combination with a $200 \mathrm{mM}$ of trehalose resulted in an increase of spermatogonia viability after recovery by more than $12 \%$ compared to the original composition of SG medium containing $10 \%$ of DMSO.

4. Obtained results on cryopreservation of spermatogonial cell lines in rats can be tested and used for cryopreservation of spermatogonia of other species of animals, including human.
Acknowledgments: We would like to thank Dr. Kent Hamra from UTSouthwestern Medical Center and research team of the Genetic Zooingeneering laboratory at Bila Tserkva National Agrarian University.

\section{REFERENCES}

Aliakbari, F., Gilani, M., Amidi F. et. al. (2016). Improving the Efficacy of Cryopreservation of Spermatogonia Stem Cells by Antioxidant Supplements. Cell Reprogram, 18(2):87-95. https://doi.org/10.1089/cell.2015.0067.

Brinster R.L, Nagano M. (1998). Spermatogonial stem cell transplantation, cryopreservation and culture. Semin Cell Dev Biol. (4):401-409. https://doi.org/10.1006/scdb.

Buchanan S., Gross S., Acker J. et. al. (2004). Cryopreservation of stem cells using trehalose: evaluation of the method using a human hematopoietic cell line.StemCellsDev.,13(3):295-305. https://doi.org/10.1089/154732804323099226 Chapman, K., Saidley-Alsaadi, D., Syvyk, A., Shirley, J., Thompson, L., Hamra, K (2011). Rat Spermatogonial Stem Cell-Mediated Gene Transfer. Advanced Protocols for Animal Transgenesis, 237-266. https://doi.org/10.1007/978-3-662-45763-4_12

Cronkhite, J., Norlander, C., Furth J., Levan, G.,Garbers, D., Hammer, R. (2005) Male and female germline specific expression of an EGFP reporter gene in a unique strain of transgenic rats. Developmental Biology, 284(1) 171-183. https://doi.org/10.1016/j.ydbio.2005.05.015

Hirabayashi M., Kato M., Ito J. et. al. (2005). Viable rat offspring derived from oocytes intracytoplasmically injected with freeze-dried sperm heads, (13): 79-85 https://www.ncbi.nlm.nih.gov/pubmed/15984166

Hochi S. K., Watanabe M., Kato M. et. al. (2008). Live rats resulting from injection of oocytes with spermatozoa freeze-dried and stored for one year. Mol Reprod Dev., (75): 890-894

Ivics, Z., Izsvak, Z., Chapman, K., Hamra, F. (2011). Sleeping Beauty transposon mutagenesis of the rat genome in spermatogonial stem cells. Nat Protoc., 6(10):15211535. https://doi.org/10.1038/nprot.2011.378

Izsvak Z., Frohlich J., Grabundzija I. et. al. (2010). Generating knockout rats by transposon mutagenesis in spermatogonial stem cells. Nat Methods, 7(6):443-445. https://doi:10.1038/nmeth.1461

Kanatsu-Shinohara M., Ogonuki N., Inoue K. et. al. (2003). Long-term proliferation in culture and germline transmission of mouse male germline stem cells. Biol Reprod. 69(2):612-6. https://doi:10.1095/biolreprod.103.017012

Kanatsu-Shinohara M., Inoue K., Ogonuki N. et. al. (2011). Serum- and feeder-free culture of mouse germline stem cells. Biol Reprod., 84(1):97-105. https://doi:10.1095/biolreprod.110.086462

Kaneko T. and Serikawa T. (2012). Successful long-term preservation of rat sperm by freeze-drying. PLoS One, 7(4): e35043. https://doi:10.1371/journal.pone.0035043

Lee Y., Kim Y., Kim B. et. al. (2013). Cryopreservation in trehalose preserves functional capacity of murine spermatogonial stem cells. PLoS One, 8(1): e54889. https://doi:10.1371/journal.pone.0054889

Mirzapour T., Movahedin M., Tengku Ibrahim T. et. al. (2013). Evaluation of the effects of cryopreservation on viability, proliferation and colony formation of human spermatogonial stem cells in vitro culture. Andrologia, 45(1):26-34 https://doi:10.1111/j.1439-0272.2012.01302.x

Motta J., Paraguassu-Braga F., Bouzas L. et. al. (2014). Evaluation of intracellular and extracellular trehalose as a cryoprotectant of stem cells obtained from umbilical cord blood. Cryobiology, 68(3):343-8. https://doi:10.1016/j.cryobiol.2014.04.007

Pegg D. Principles of cryopreservation. (2015). Methods Mol Biol., 1257:3-19. https://doi:10.1007/978-1-4939-2193-5_1

Rodriguez-Sosa J., Dobson H., Hahnel A. (2006). Isolation and transplantation of spermatogonia in sheep. Theriogenology, 66(9):2091-103. https://doi:10.1016/j.theriogenology.2006.03.039

Rodrigues J., Paraguassu-Braga F., Carvalho L. et. al. (2008). Evaluation of trehalose and sucrose as cryoprotectants for hematopoietic stem cells of umbilical cord blood. Cryobiology, 56(2):144-51. https://doi:10.1016/j.cryobiol.2008.01.003

Syvyk, A., Djachenko, L., Syvyk, T. (2017). Transgenesis through the spermatogonia stem cells in the animals and prospects of its application in Bila Tserkva NAU. Collection of scientific works of Bila Tserkva NAU, 1(134), 5-12.

Syvyk T., Syvyk A. (2018). Customized transgenesis via modification of spermatogonial stem cells. Journal of microbiology, biotechnology and food sciences, 7 (5), 475-479. https://doi:10.15414/jmbfs.2018.7.5.475-479

Stacey G., Masters J. (2008). Cryopreservation and banking of mammalian cell lines. Nat Protoc., 3(12):1981-9. https://doi:10.1038/nprot.2008.190

Stacey G., Dowall S. (2007). Cryopreservation of primary animal cell cultures. Methods Mol Biol., 368:271-81. https://doi:10.1007/978-1-59745-362-2 19

Shinohara T., Orwig K., Avarbock M. et. al. (2000). Spermatogonial stem cell enrichment by multiparameter selection of mouse testis cells. Proc Natl Acad Sci U S A, 97(15):8346-8351. https://doi.org/10.1073/pnas.97.15.8346

Wu X., Goodyear S., Abramowitz L. et. al. (2012). Fertile offspring derived from mouse spermatogonial stem cells cryopreserved for more than 14 years.

Hum Reprod., 27(5):1249-59. https://doi:10.1093/humrep/des077

Wu, Z., Falciatori, I., Molyneux, L., Richardson, T. and others. (2009). Spermatogonial culture medium: an effective and efficient nutrient mixture for culturing rat spermatogonial stem cells. Biol Reprod., 81, 77-86. https://doi.org/10.1095/biolreprod.108.072645 